\title{
APRESENTAÇÃO
}

\section{DOSSIÊ: O GOVERNO VARGAS E OS 80 ANOS DE ESTADO NOVO}

"O Estado Novo, de novo, e de novo..."

Cássio A. A. Albernaz ${ }^{1}$

Doutor em História - PUCRS

E-mail: cassioalbernaz@hotmail.com

A Revista Oficina do Historiador apresenta ao leitor, neste número, um dos temas seminais da historiografia brasileira contemporânea: o Estado $\mathrm{Novo}^{2}$, nome pelo qual ficou conhecida a experiência histórica brasileira entre os anos 1937-1945. Para além da efeméride dos seus 80 anos, o Estado Novo, de um modo geral, é percebido através dos reflexos de disputas políticas, de debates acadêmicos, e de designações que vão sendo sobrepostas no tempo. Por isso um tema sempre atual.

Além da já tradicional ruptura com a chamada República "Velha", o Estado Novo é concebido como momento do engendramento do dualismo brasileiro, opondo os setores agrário-latifundiários aos setores urbano-industriais. ${ }^{3} \mathrm{O}$ regime também é interpretado como ditatorial, autoritário, populista, desenvolvimentista, antiliberal, modernizante, industrializante, intervencionista, fascista, corporativista, nacionalista, popular, trabalhista, e etc. Termos e interpretações muitas vezes complementares e tantas outras, antinômicos e conflitantes. Portanto, campo de disputa política e de memória, o Estado Novo é atualizado no presente e

\footnotetext{
${ }^{1}$ Professor colaborador junto ao Programa de Pós-Graduação em História da PUCRS. Pós-Doutorando em História pela PUCRS/PNPD/Capes.

${ }^{2}$ Cabe lembrar que o nome oficial do regime implantado em 10 de novembro de 1937 era Estado Nacional, como aparecia na Constituição outorgada por Getúlio Vargas. Estado Novo era o nome do regime implantado em Portugal, 4 anos antes por Salazar. Entretanto, no Brasil, a imprensa e os intelectuais trataram o regime como o Estado Novo brasileiro, em referência ao Salazarismo e como superação da República Velha, e acabou se tornando o nome popular do regime.

${ }^{3}$ FAUSTO, Bóris. (1994).
}

Oficina do Historiador, Porto Alegre, EDIPUCRS, v. 10, n. 2, jul./dez. 2017, 
diluído na chamada "Era Vargas", ora como um legado que deve ser abandonado, ora com um legado legítimo de ser mobilizado. ${ }^{4}$

Nessas disputas nada se dá ao acaso. O próprio Estado Novo e seus ideólogos trataram de gerar uma memória e uma interpretação de si. Primeiramente, buscando legitimar-se frente aos seus adversários, os "comunistas", categoria ampla e difusa, mas eficiente para legitimar o Estado de exceção frente aos "inimigos externos", e, depois, as oligarquias regionais, ligadas ao federalismo, ao atraso, e a uma tendência centrífuga da Nação. Assim, a Constituição de 1937, no discurso de seus ideólogos, buscava reparar esses erros, fortalecendo o poder do Estado, centralizando o poder no executivo e aumentando a capacidade de intervenção estatal em todos os setores da vida social. ${ }^{5}$

Dessa forma, o discurso estadonovista também buscava legitimação a partir de uma interpretação da realidade histórica que operava uma leitura dos acontecimentos. Nesse sentido, repetiam sistematicamente que o golpe era um desdobramento natural, e mesmo inevitável, da Revolução de 1930, sendo o Estado Novo o garantidor dos objetivos de 1930, corrigindo os desvios de 1932, e da Constituição de 1934, e justificando seu autoritarismo. É claro que esse discurso estava sendo alicerçado há mais tempo, principalmente nas críticas dirigidas à experiência da Primeira República e à Constituição de 1891 e seu arcabouço institucional liberal.

Outro sentido para justificar o Estado Novo era o contexto internacional, a constatação das transformações mundiais no pós-Primeira Guerra mundial alterando as condições do comércio internacional, o equilíbrio de forças entre as nações, e o surgimento de modelos políticos que se apresentavam como mais funcionais para responder a crises, principalmente, a crise liberal, tais como o fascismo e o nazismo. Dessa forma, a emergência de uma sociedade de massas vem pari passu ao crescimento de um discurso autoritário que se opõe ao chamado “idealismo liberal”. Nesse sentido, o Brasil apenas seguiu a vaga internacional ao implementar o Estado Novo e ao buscar o chamado "idealismo orgânico" buscando reformar as bases do pacto republicano numa nova ordem. ${ }^{6}$

\footnotetext{
${ }^{4}$ Penso aqui nas referências explicitas dos ex-presidentes Fernando Henrique Cardoso, que situava a necessidade de "acabar com a Era Vargas”, e de Luís Inácio Lula da Silva, de ser um “ continuador do varguismo".

${ }^{5}$ Dentre os principais ideólogos do Estado Novo estão Oliveira Viana, Francisco Campo e Azevedo Amaral.

${ }^{6}$ Os termos "idealismo orgânico" e "idealismo constitucional" pertencem a analise de Oliveira Viana. Ver: VIANA, Oliveira. O idealismo da constituição. São Paulo: Cia. Editora Nacional, 1939. $2^{\text {a }}$ edição.
}

Oficina do Historiador, Porto Alegre, EDIPUCRS, v. 10, n. 2, jul./dez. 2017, 
O Estado Novo tem sido amplamente analisado pela historiografia contemporânea como um tema-chave para compreensão da relação entre Estado e sociedade no Brasil. Entretanto, ainda é uma temática de estudos relativamente recente. Em início dos anos 1990, René Gertz, no texto, Estado Novo: um inventário historiográfico ${ }^{7}$, ressaltava os poucos estudos sobre o período e a diluição do Estado Novo na Era Vargas. De lá para cá muita coisa mudou, como já ressaltava Maria Helena Capelato, no texto Estado Novo. Novas histórias ${ }^{8}$, chamando atenção para uma profusão de estudos sobre o Estado Novo, já em fins dos anos 1990.

Com essas breves observações introdutórias, fica evidente a imensa carga de disputas políticas e memoriais que o Estado Novo contém e que ainda é mobilizada na atualidade. Por isso, mostra-se uma temática seminal da historiografia contemporânea brasileira, sempre revisitada para a compreensão da nossa história.

O Dossiê O governo Vargas e os 80 anos de Estado Novo é composto por cinco artigos de diferentes temáticas que refletem essa produção recente. No artigo de abertura, $O$ declínio do Estado Novo, a Legislação Eleitoral e a atuação Otávio Mangabeira na campanha da UDN baiana (1945), Eliana Evangelista Batista analisa os impactos do Ato de ${ }^{\circ} 9$ e do Decreto-Lei $\mathrm{n}^{\mathrm{o}} 7.856$ sobre as eleições de 1945 , no contexto de crise estadonovista, e sobre os partidos políticos de oposição a Vargas, sobretudo a UDN baiana. Ainda a respeito da UDN baiana, a autora também analisa a relação do partido com seus eleitores e as estratégias dos seus dirigentes frente à nova legislação eleitoral. Nesse sentido, a autora destaca a atuação oposicionista de Otávio Mangabeira a Vargas, durante os anos 1930 e 1940, e a articulação da UDN baiana frente à reorganização político-partidária de 1945.

O mito da união nacional: a construção das "famílias brasileiras" na ditadura do Estado Novo, de Fábio Roberto Wilke, analisa a construção da mitologia política associada a Getúlio Vargas, o "pai dos pobres” e a construção retórica da política estadonovista em relação à família. Para isso, analisa o modo como o Estado Novo interferiu nela através de uma concepção pública, ou materializada, demonstrando ações efetivas do Estado, notadamente através de políticas públicas que buscaram transformar a força de trabalho. No mesmo sentido, o autor também analisa como o Estado Novo utilizou-se de uma ideia privada de família, para criar uma retórica política de união nacional através do trabalho.

\footnotetext{
${ }^{7}$ SILVA, Jorge. L. Werneck. (org.) O feixe e o prisma. Uma revisão do Estado Novo. Rio de Janeiro: Jorge Zahar Editor, 1991.

${ }^{8}$ FREITAS, Marcos Cézar. (org.) Historiografia em Perspectiva. São Paulo, Contexto, 1998.
}

Oficina do Historiador, Porto Alegre, EDIPUCRS, v. 10, n. 2, jul./dez. 2017, 
Em Considerações sobre justiça de transição no Estado Novo, Enio Viterbo analisa o processo de redemocratização, em 1945, e a carência de uma justiça transicional, principalmente, para as violações de Direitos Humanos cometidas durante o Estado Novo. Para o autor, o modelo de "transição pactuada" acabou sendo responsável pela impunidade dos agentes estatais durante o período ditatorial. Para tanto, o autor analisa a doutrina internacional sobre justiça de transição empreendendo uma análise de direito e história comparada com a Itália pós Mussolini.

Já Marina Contin Ramos, no artigo Cruzeiro: a renovação monetária no Brasil e o Governo Vargas, analisa a renovação do sistema monetário nacional, através do lançamento de uma nova moeda, o cruzeiro, em 1942, pelo Decreto Lei 4971. Nesse sentido, ressalta as questões inflacionárias e a desvalorização que levaram à mudança monetária, seus estudos técnicos e debates, tendo por objetivo principal mostrar que a renovação no nosso meio circulante não implicava em uma questão apenas econômica, mas também numa questão simbólica que envolvia o fortalecimento do Estado e a formação da nação, questões caras ao projeto varguista.

$\mathrm{O}$ artigo que encerra esse dossiê é $O$ "bom imigrante": as religiosidades católica e protestante luterana como fator de identidade nacional (ou não) durante o Estado Novo. O autor, Sérgio Luiz Marlow, analisa a chamada "Campanha de Nacionalização" durante o Estado Novo, buscando compreender como o processo de nacionalização impactou os protestantes luteranos através da importância que o Catolicismo adquiria como uma espécie de fomentador da identidade nacional. Mais especificamente, o autor busca compreender de que forma um dos sínodos luteranos no Brasil, o Sínodo de Missouri, percebia a possível ligação entre o Estado Brasileiro e o Catolicismo Romano, quanto à perspectiva do nacionalismo que se desejava impor.

Assim, desejo que esse dossiê entre nessa senda de produções relevantes sobre a temática do Estado Novo, ampliando os horizontes de análise dentro do campo da história, e mais particularmente, de uma história recente do Brasil. Entendo que esse dossiê contribui em duas perspectivas: primeiramente, ao trazer novos debates e novas reflexões; e ainda, abrindo possibilidades de pesquisas futuras sobre a experiência histórica do Estado Novo.

Oficina do Historiador, Porto Alegre, EDIPUCRS, v. 10, n. 2, jul./dez. 2017, 